\title{
A PRODUÇÃO SOCIAL DO ESPAÇO E O ENSINO DA CIDADE DE DUQUE DE CAXIAS PELAS IMAGENS
}

\author{
Edson José Diniz Leite ${ }^{1}$ \\ Ana Claudia Ramos Sacramento ${ }^{2}$
}

\begin{abstract}
Resumo: A educação geográfica visa estimular a capacidade reflexiva, analítica e crítica dos estudantes referente aos fenômenos geográficos que ocorrem na escala local e, também, no âmbito global. Nessa lógica, estudar a cidade, nesse caso, o município de Duque de Caxias, torna-se um importante instrumento para o processo de ensino-aprendizagem $\mathrm{e}$, consequentemente, para a construção do conhecimento geográfico dos estudantes. Isto se dá, pois, além de ser lócus de suas práticas espaciais, contém importantes elementos que podem ser dialogados no decorrer das aulas, como: os espaços de lutas e contradições; a presença dos símbolos e as questões econômicas, sociais, urbanas e ambientais. Desta forma, o uso de imagens, nesse trabalho, para a apresentação dos conteúdos sobre Duque de Caxias, foi um recurso didático, como uma mediação didática. Como metodologia de pesquisa, buscou-se trabalhar com o referencial teórico-metodológico qualitativo - o estudo de caso, para problematizar o porquê e o como relacionar os conteúdos e os conceitos geográficos ao espaço cotidiano dos alunos. Como resultado foi possível observar a participação ativa dos estudantes com as atividades realizadas, uma vez que aqueles apresentaram um nível maior de opiniões, questionamentos e apresentações de soluções para as problemáticas discorridas, além de favorecer uma maior interação e diálogo entre docente e o discente.
\end{abstract}

Palavras-chave: Produção do Espaço. Ensino de Cidade. Imagens.

\section{THE SOCIAL PRODUCTION OF SPACE AND THE EDUCATION OF THE CITY OF DUQUE DE CAXIAS BY THE IMAGES}

\begin{abstract}
The geographical education aims at stimulating students' reflexive, analytical and critical capacity regarding geographic phenomena occurring locally and globally. In this logic, studying the city, in this case, the municipality of Duque de Caxias, becomes an important instrument for the teaching-learning process and, consequently, for the construction of the students' geographical knowledge. This is, therefore, as well as being a locus of its spatial practices, it contains important elements that can be dialogued in the course of classes, such as: the spaces of struggles and contradictions; the presence of symbols and economic, social, urban and environmental issues. In this way, the use of images, in this work, for the presentation of the contents on Duque de Caxias, was a didactic resource, like didactic mediation. As a research methodology, we sought to work with the qualitative theoretical-methodological framework the case study, to problematize the why and how to relate the contents and the geographic concepts to the daily space of the students. As a result, it was possible to observe the active

1 Licenciado em Geografia pela Universidade do Estado do Rio de Janeiro. E-mail: edsondinizgeo@gmail.com

${ }^{2}$ Doutora em Geografia pela Universidade de São Paulo (2012) e Mestre em Educação pela Faculdade de Educação da USP (2007). Docente na UERJ-FFP no Departamento de Geografia com atuação na área de Ensino de Geografia, na graduação, na especialização e no mestrado, principalmente nos seguintes temas: Educação Geográfica, Formação de Professor, Currículo e Didática de Geografia. Coordenadora Projetos FAPERJ e CNPQ. E-mail: anaclaudia.sacramento@hotmail.com
\end{abstract}




\section{REVISTA ELETRÔNICA \\ DA GRADUAÇÃO/PÓS-GRADUAÇÃO EM EDUCAÇÃO UFG/REJ}

\section{ITINERPARUS REFLECTIONIS}

ISSN. 1807-9342

Volume 14, N. 2, 2018

participation of the students with the activities carried out, since those presented a higher level of opinions, questionings and presentations of solutions to the problems discussed, besides favoring a greater interaction and dialogue between teacher and student.

Keywords: Production of space. City education. Images.

\section{INTRODUÇÃO}

Este trabalho resulta da pesquisa de conclusão do projeto PIBID (Programa Institucional de Bolsa de Iniciação à Docência), no Curso de Geografia do Departamento de Geografia da UERJ-FFP. A busca por propor novas e diferentes propostas teórico-metodológicas referentes ao ensino de geografia é necessária para se pensar uma disciplina que promova a articulação entre teoria e prática; principalmente com relação à temática da Cidade e do Urbano.

Promover novas propostas metodológicas de aprendizagem contribui para um ensino mais crítico e reflexivo da Geografia por parte dos estudantes, os quais podem observar a relação dos conceitos e dos conteúdos com os fenômenos geográficos que ocorrem no seu cotidiano, permitindo ainda a sua participação ativa nas atividades e maior diálogo entre professor e aluno (SACRAMENTO, 2012, 2014).

Assim sendo, ao considerar o cotidiano dos estudantes na educação geográfica, ajuda-se a superar as aprendizagens enfadonhas que estão entranhadas na geografia escolar, aproximando os conteúdos e os conceitos geográficos à realidade deles. Nessa lógica, o estudo da cidade se torna um elemento importante para a educação geográfica, uma vez que neste ocorrem as práticas espaciais dos estudantes e os diversos fenômenos geográficos, possibilitando a articulação do conhecimento empírico com o conhecimento científico que serão adquiridos no âmbito escolar (CAVALCANTI 2012; SACRAMENTO, 2014).

Partindo da experiência com o PIBID, optou-se por utilizar como objeto de estudo para esta pesquisa o município de Duque de Caxias, por ser parte importante da Região Metropolitana do Rio de Janeiro, e local em que se percebeu a grande dificuldade dos professores em despertar nos alunos o interesse pela geografia.

A respectiva pesquisa foi trabalhada a partir da metodologia das oficinas pedagógicas, neste caso, o uso de imagens. Nesse sentido, para a realização do referido trabalho, o recorte espacial foi feito em duas turmas do terceiro ano do ensino médio, do Colégio Estadual Nova América. O objetivo é compreender a importância que a cidade 


\section{REVISTA ELETRÔNICA \\ DA GRADUAÇÃO/PÓS-GRADUAÇÃO EM EDUCAÇÃO UFG/REJ}

\section{ITHEERAPIIIS REFLCTIONIS}

ISS N. 1807-9342

Volume 14, N. 2, 2018

de Duque de Caxias possui na educação geográfica, permitindo relacionar os conteúdos/conceitos geográficos aos fenômenos que ocorrem tanto na escala local quanto global, a partir do uso de imagens.

Desta forma, o texto está dividido em três momentos: no primeiro, analisa-se a produção do espaço no município de Duque de Caxias; no segundo, reflete-se acerca da cidade como um importante elemento para a educação geográfica, pois é o espaço cotidiano das práticas espaciais dos estudantes, o que pode causar a curiosidade por assuntos a respeito daquela, abrindo espaços para diálogos, questionamentos e opiniões. No terceiro, destaca-se o uso das imagens como importante recurso didático no processo de ensino sobre a cidade.

\section{A PRODUÇÃO DO ESPAÇO DO MUNICÍPIO DE DUQUE DE CAXIAS-RJ}

A discussão teórica referente ao espaço urbano envolve uma grande quantidade de diferentes ciências e autores que buscam compreender como se dá a inserção da lógica capitalista na sua produção, destacando as suas consequências em distintos âmbitos. Na análise de Corrêa (1989), o espaço urbano capitalista é algo muito complexo, possuindo múltiplas funções e sentidos, e onde diferentes grupos se apropriam deste espaço de acordo com suas necessidades e interesse.

O espaço urbano capitalista - fragmentado, articulado, reflexo, condicionamento social, cheio de símbolos e campos de lutas - é um produto social, resultante de ações acumuladas através do tempo, e engendradas por agentes que produzem e consomem espaço (CORRÊA, 1989, p. 11).

A partir da citação do autor, pode-se afirmar que a paisagem expressa no espaço geográfico não é homogênea, mas transformada em consequência das diferentes relações sociais que ocorreram em contextos históricos diferentes. Assim, observa-se que, no espaço urbano capitalista, a organização da cidade ocorre a partir do uso diferenciado, fragmentado e complexo do solo, onde existem as áreas industriais, agrícolas e residenciais. Ao mesmo tempo em que este é fragmentado, é articulado, por exemplo, a partir dos meios de transporte, por onde a população se desloca diariamente.

Atualmente, o capitalismo se tornou um modelo econômico expansivo e volátil, criando uma força permanentemente revolucionária, que incessante e constantemente, 


\section{REVISTA ELETRÔNICA \\ DA GRADUAÇÃO/PÓS-GRADUAÇÃO EM EDUCAÇÃO UFG/REJ}

\section{ITINERARPIUIS REFLECTIONIS}

ISSN. 1807-9342

Volume 14, N. 2, 2018

reforma o mundo em que vivemos (HARVEY, 2005). Esses adjetivos referentes ao capitalismo se mostram necessários à transformação constante do espaço urbano por diferentes atores, a fim de criar mecanismos que favoreçam à adaptação e à reprodução do capital.

Nesse contexto, Corrêa (1989) enfatiza que os proprietários dos meios de produção, sobretudo os grandes industriais, os proprietários fundiários, os promotores imobiliários, o Estado e os grupos excluídos, são os principais agentes produtores do espaço urbano. Os três primeiros são os grandes utilizadores do solo urbano por deterem o maior grau de capital, possibilitando a sua transformação com maior rapidez e de acordo com suas necessidades. O Estado, mesmo sendo um órgão público, é o principal aliado dos grandes detentores dos meios de produção, possuindo instrumentos capazes de organizar o espaço (regulamentação do solo, controle de limitação dos preços das terras, investimento público em infraestrutura e outros), utilizando-se de mecanismos que facilitam a reprodução do capital. Por outro lado, os grupos excluídos representam a contradição que é a lógica capitalista, uma dialética que produz grandes desigualdades, gerando riqueza para um grupo (empresários) e pobreza para outros.

É possível observar que a produção do espaço urbano ocorre de forma contraditória, gerando desigualdades espaciais, sociais e ambientais. Deste modo, as desigualdades socioespaciais expressas na cidade são um dos exemplos clássicos da exclusão e contradição que é a produção do espaço urbano. Em consequência, segundo Lefebvre (2008), essas desigualdades entre riqueza e pobreza, poderosos e oprimidos, acende a necessidade de haver lutas de classes nas cidades.

A cidade conserva um caráter orgânico de comunidade, que lhe vem da aldeia, e que se traduz na organização corporativa. A vida comunitária (comportando assembleias gerais ou espaciais) em nada impedem as lutas de classes. Pelo contrário. Os violentos contrastes entre a riqueza e a pobreza, os conflitos entre os poderosos e os oprimidos não impedem nem o apego à Cidade, nem a contribuição ativa para a beleza da obra. No contexto urbano, as lutas de facções, de grupos, de classes, reforçam o sentimento de pertencer (LEFEBVRE, 2008, p.13).

A segregação socioespacial é o elemento mais fácil e visível de se encontrar nas cidades, representando a materialização das desigualdades e contradição que o capital produz. Nesse contexto, Souza (2005) afirma que a segregação socioespacial não é um 


\section{REVISTA ELETRÔNICA \\ DA GRADUAÇÃO/PÓS-GRADUAÇÃO EM EDUCAÇÃO UFG/REJ}

\section{Truerpows REFLECTONIS}

ISSN. 1807-9342

Volume 14, N. 2, 2018

processo recente da história da urbanização. Aquela remonta desde a antiguidade, em que grupos, devido a sua pobreza, etnia, ou outro fator, eram forçados a viver em certas áreas com menos infraestrutura e mais insalubridade e, ao mesmo tempo, sendo excluídos de certos espaços da cidade reservados à classe dominante. A partir do século XIX, com o surgimento do moderno capitalismo na Europa, houve transformações importantes no padrão de segregação, pois a diferença entre ricos e pobres, a separação do local de trabalho e de moradia passaram a acentuar-se.

Assim, a segregação socioespacial se tornou atualmente um produto da cidade, sendo uma das principais problemáticas urbanas.

A segregação residencial é um resultado de vários fatores, os quais em si, são altamente problemáticas: a pobreza (e do racismo sobretudo em uma situação como o dos Estados Unidos); ao papel do Estado, na criação de disparidades espaciais em matéria de infraestrutura e no favorecimento dos moradores de elite (principalmente em um país como o Brasil) (SOUZA, 2005, p. 83-84).

A partir da análise de Souza (2005), conclui-se que o caso da segregação nas cidades brasileiras está ligado principalmente à questão do poder aquisitivo. Nesse sentido, quanto maior o poder de compra da população de um referido bairro, maiores serão os investimentos em saúde, educação, infraestrutura e saneamento. Por outro lado, se o bairro concentra uma população de baixo poder aquisitivo, a ausência desses bens tende a aumentar. Assim, observa-se que o Estado é um dos principais agentes responsáveis pelo aumento da segregação no país, visto que sua maior função é criar mecanismos estruturais para a acumulação do capital, e favorecer aqueles que detêm os meios de produção.

Por conseguinte, as problemáticas ambientais são também resultantes contraditórias da forma com que ocorre a produção do espaço urbano. Nessa perspectiva, na visão dos detentores dos meios de produção, o espaço urbano e a natureza possuem valor de troca, sendo vistos como recursos para a reprodução constante do capital e acumulação futura de lucros.

Pode-se afirmar a partir de Corrêa (1989) e Lefebvre (2008) que o espaço urbano é o condicionamento social e reflexo das relações sociais. Por isso, observa-se que a transformação do espaço geográfico e a existência das contradições espaciais são 


\section{REVISTA ELETRÔNICA}

DA GRADUAÇÃO/PÓS-GRADUAÇÃ̃O EM EDUCAÇÃO

UFG/REJ

\section{ITHEPAPIIS REFLECTIONIS}

ISS N. 1807-9342

Volume 14, N. 2, 2018

elementos importantes e permanentes, sendo essenciais para a reprodução do capital. Assim, ao mesmo tempo em que existem nas cidades condomínios de luxo, fechados com todo serviço básico; no outro extremo vê-se outra realidade, com bairros sem saneamento básico, população enfrentando transportes lotados, entre outras problemáticas. Ademais, observa-se o uso da natureza somente como recurso, a fim de produzir cada vez mais mercadorias e acumular lucros, sem se preocupar com as inúmeras consequências ambientais. Assim sendo, essas contradições não são uma problemática para o capitalismo, mas soluções que este encontrou para a acumulação do capital.

Com relação ao município de Duque de Caxias, este fica situado na Baixada Fluminense, pertencendo à região metropolitana do Rio de Janeiro. Fundado em 31 de dezembro de 1943, possui quase um milhão de habitantes distribuídos em um território de $465 \mathrm{Km}^{2}$ (cmdc.rj.gov.br). O mesmo configura como importante ator econômico não só para o estado do Rio de Janeiro, mas para todo o Brasil.

Pode-se afirmar que, mesmo antes da fundação do município, esse recebeu investimentos maciços de capitais industriais em um curto espaço de tempo, tendo sido importantes para a transformação do seu espaço geográfico. Nessa perspectiva, o seu processo de industrialização pode ser dividido em três períodos: o primeiro, com a instalação da Fábrica Nacional de Motores, Xerém (1942), período em que o mundo vivia sobre a influência da Segunda Guerra Mundial. O segundo, com a inauguração da Companhia União Manufatura de Tecidos (1949), no bairro Centenário e, por último, com a consolidação da instalação da Refinaria Duque de Caxias (1961).

Como consequência do rápido processo de industrialização em um curto espaço de tempo, Duque de Caxias se tornou um município economicamente potente para o estado do Rio de Janeiro e também para o Brasil. Ao analisar os dados do IBGE (2010) sobre o PIB dos municípios brasileiros, Duque de Caxias concentrava o $2^{\circ}$ maior PIB interno bruto do Estado e o $18^{\circ}$ do país, além de ser o $2^{\circ}$ maior arrecadador de ICMS (Impostos Sobre Circulação de Mercadorias e Serviços), perdendo somente para a capital do Rio de Janeiro. 


\section{REVISTA ELETRÔNICA}

DA GRADUAÇÃO/PÓS-GRADUAÇÃO EM EDUCAÇÃO

UFG/REJ
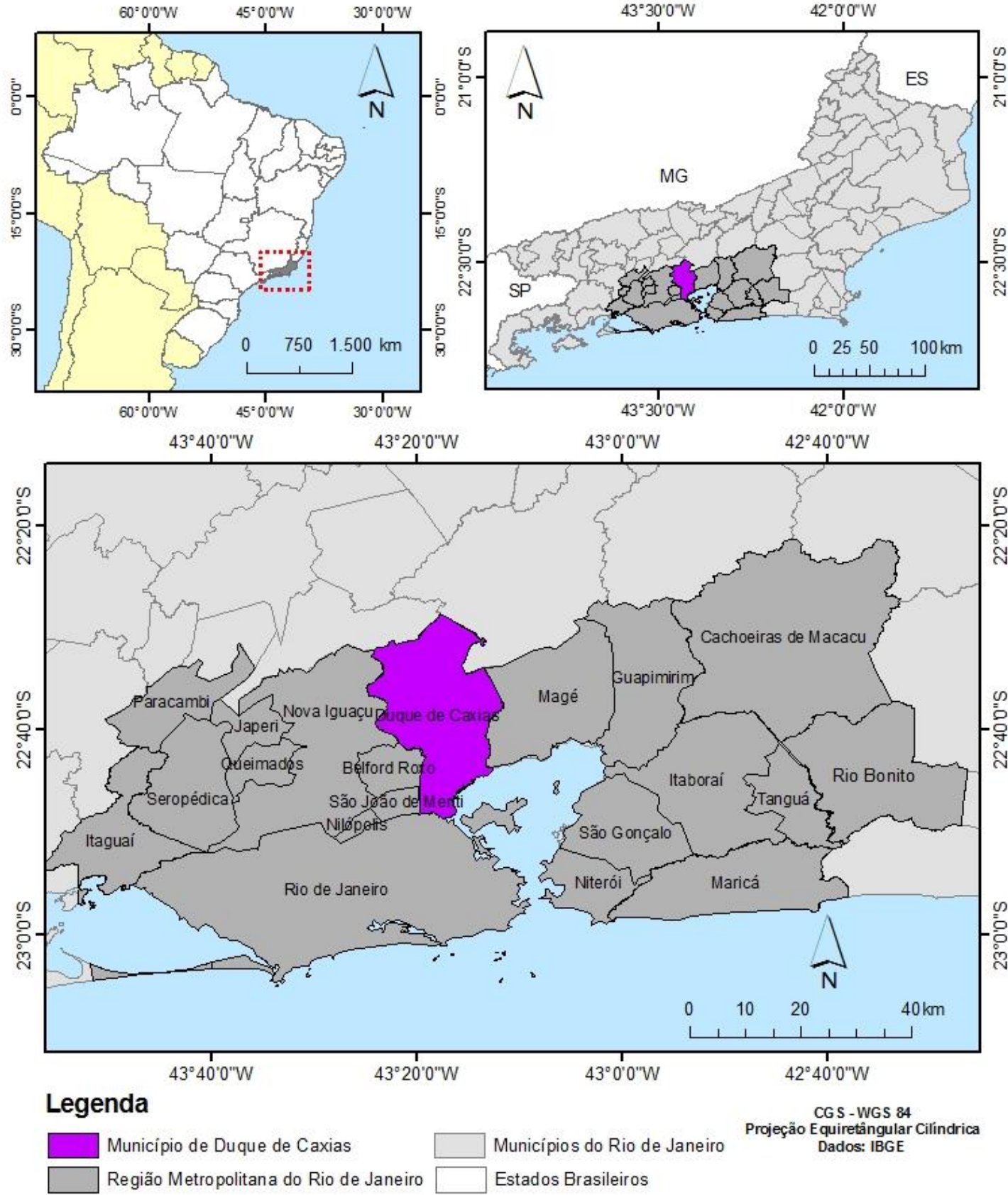

Figura 1: Mapas do Brasil, Estado do Rio de Janeiro e Região Metropolitana.

Fonte: Mapa elaborado por SEABRA (2015)

Os investimentos estatais no território caxiense foram um dos principais elementos que provocou a ascensão industrial do município. Juscelino Kubitschek (1956-1961), no seu período de governo, criou o Plano de Metas que visava a 


\section{REVISTA ELETRÔNICA \\ DA GRADUAÇÃO/PÓS-GRADUAÇÃO EM EDUCAÇÃO UFG/REJ}

\section{ITINEPARIUS REFLECTIONIS}

ISSN. 1807-9342

Volume 14, N. 2, 2018

investimentos importantes para o desenvolvimento do país nas áreas de energia, transporte e indústria de base.

Fazendo parte de um dos principais setores de investimentos do Plano de Metas, JK construiu no município de Duque de Caxias em 1961, uma das primeiras e principais refinarias da Petrobrás, a REDUC. A criação da REDUC trouxe transformações espaciais importantes para o município, especialmente em Campos Elíseos, distrito no qual se encontra a refinaria, formando naquela região um complexo industrial com aproximadamente 128 indústrias ligadas principalmente ao setor petroquímico.

É importante argumentar que a instalação da REDUC não foi o único fator importante para o crescimento industrial do município de Duque de Caxias. Se olharmos o mapa da região metropolitana, observaremos que o município se localiza no centro geográfico metropolitano e próximo às principais vias expressas (BR 040 - Rio de Janeiro - Juiz de Fora, Avenida Brasil, Linha Vermelha e Rodovia Presidente Dutra). Além destes, ao aeroporto internacional do Rio de Janeiro, favorecendo o transporte de produtos para os mercados consumidores do país. Harvey (2005) destaca a importância dos fluxos para a acumulação e expansão do capital.

O modo capitalista de produção fomenta a produção de formas baratas e rápidas de comunicação e transporte, para que o "produto direto possa ser realizado em mercados distantes e em grandes quantidades", ao mesmo tempo em que novas "esferas de realização para o trabalho, impulsionadas pelo capital" podem se abrir. Portanto, a redução nos custos de realização e circulação ajuda a criar espaço novo para a acumulação do capital. Reciprocamente, a acumulação de capital se destina a ser geograficamente expansível, e faz isso pela progressiva redução do custo de comunicação e transporte (HARVEY, 2005, p.48).

A partir do que afirma o autor, observa-se que os fluxos (meios de transporte, comunicações, entre outros) são um elemento importante para a acumulação do capital e organização espacial. Estes permitem, por exemplo, que os produtos sejam levados em grandes quantidades a mercados consumidores de forma mais rápida, barateando o preço final das mercadorias e expandindo a acumulação do capital. Por isso, Duque de Caxias se tornou um importante polo para instalação de empresas e exploração do capital, uma vez que está localizado próximo a aeroportos e estradas federais e estaduais, permitindo que os principais produtos fabricados no município (metalúrgico, 


\section{REVISTA ELETRÔNICA \\ DA GRADUAÇÃO/PÓS-GRADUAÇÃO EM EDUCAÇÃo \\ UFG/REJ}

\section{ITHEERARIIUS \\ REFLCTIONIS}

ISS N. 1807-9342

Volume 14, N. 2, 2018

móveis, alimentos e outros) sejam escoados de forma rápida para os maiores mercados consumidores do Brasil, como São Paulo, Rio de Janeiro e Minas Gerais.

O crescimento industrial do município de Duque de Caxias é um fenômeno ainda visível no seu espaço. Por isso, o Estado ainda é o principal influenciador e aliado do capital na produção espacial do município.

No ano de 2014, o governo do Estado do Rio de Janeiro inaugurou o Arco Metropolitano, uma estrada que corta vários municípios da região metropolitana, interligando as principais indústrias (Porto de Itaguaí, Refinaria Duque de Caxias e o Complexo Petroquímico do Rio de Janeiro) e dinamizando a economia do estado do Rio de Janeiro, em especial a região da Baixada Fluminense. Outro grande objetivo desde projeto é diminuir o trânsito nas principais vias, como a Avenida Brasil, a Linha Vermelha e a Ponte Rio Niterói; evitando, assim, que muitos veículos pesados passem nessas vias e optem, dessa forma, pelo arco metropolitano.

É perceptível que o projeto do Arco Metropolitano foi criado pelo Estado com o intuito econômico de adaptar o espaço para a reprodução do capital. Nesse quadro, a construção da estrada foi motivada também por pressões dos grandes empresários, uma vez que estavam perdendo dinheiro com os intensos congestionamentos nas estradas do estado. Assim sendo, percebe-se, conforme a análise de Corrêa (1989), que o Estado regente no atual contexto urbano e da economia, está aliado à lógica capitalista, criando mecanismos estruturais no espaço, a fim de favorecer a fluidez de mercadorias e a acumulação do capital.

No contexto do município de Duque de Caxias, segundo o site do Fórum Rio (2015), o Arco Metropolitano passa por bairros rurais e com baixa densidade demográfica, permitindo que essas localidades e regiões próximas recebam a instalação futura de várias empresas. Portanto, o município é o que possui a maior disponibilidade de área para a criação de distritos industriais. Consequentemente, será o município a receber os maiores volumes de investimentos que transformarão a paisagem do espaço rural e urbano nos próximos anos em vários âmbitos.

Pode-se notar que tanto no passado quanto no período atual, a ação do Estado foi e é um importante elemento na produção espacial de Duque de Caxias. Por consequência, o município passou a se inserir no contexto que Santos (2008) denomina 


\section{REVISTA ELETRÔNICA \\ DA GRADUAÇÃO/PÓS-GRADUAÇÃOO EM EDUCAÇÃO}

UFG/REJ

\section{TTHERAPIIIS \\ REFLECTIONIS}

ISS N. 1807-9342

Volume 14, N. 2, 2018

de região concentrada, o que intensifica o fluxo de investimentos de empresas, e consequentemente, o movimento migratório para a cidade.

Trata-se de uma área contínua, onde uma divisão do trabalho mais intensa que no resto do país garante a presença conjunta das variáveis mais modernas - uma modernização generalizada - ao passo que, no resto do país, a modernização é seletiva, mesmo aquelas manchas ou pontos cada vez mais extensos e numerosos onde estão presentes grandes capitais, tecnologias de ponta e modelos elaborados de organização (SANTOS, 2008, p.42-43).

O contexto de migração para o município não é um fenômeno atual, ocorrendo mesmo antes de sua emancipação. Braz; Almeida (2010) destacam algumas das razões que propiciaram tal movimento migratório: a) o processo de saneamento básico pelo qual passou a região da Baixada Fluminense no início do século XX, com o então governador Manoel de Matos Duarte Silva; b) a abertura da estrada Rio-Petrópolis (atual BR-040), em 1928, que valorizou o solo das áreas ao entorno da estrada, c) e a presença de poucas atividades industriais que estavam voltadas para pequenas empresas têxtis, de vidros, produtos químicos e farmacêuticos, aumentando o número de loteamento na região. Esse fluxo populacional se intensificou ainda mais nos anos posteriores na década de quarenta, com a instalação das seguintes estatais: Fábrica Nacional de Motores (FNM, 1942), em Xerém (1942) e a Refinaria Duque de Caxias (Reduc, 1961), em Campos Elíseos, que tende a crescer na atualidade.

Por fim, é importante salientar que o movimento populacional para o município não foi acompanhado de um planejamento urbano. Duque de Caxias passou por um processo de crescimento urbano desordenado, assim como a maioria dos municípios brasileiros. Muitos loteamentos que viraram bairros não contavam e ainda não contam com a presença de água, iluminação, calçamento e rede de esgoto.

Assim, após essa breve contextualização a respeito da produção do espaço urbano de Duque de Caxias, partindo-se das análises de Braz; Almeida (2010), Lefebvre (2011) e Corrêa (1989), é possível observar que o espaço urbano do município é inserido em uma lógica capitalista, cujos investimentos feitos pelo Estado sempre privilegiaram a reprodução do capital. É notável que a conjuntura econômica do município apresenta indicadores expressivos e importantes para o estado e o país. Por 


\section{REVISTA ELETRÔNICA \\ DA GRADUAÇÃO/PÓS-GRADUAÇÃO EM EDUCAÇÃO UFG/REJ}

\section{ITINERARPIUIS REFLECTONIS}

ISSN. 1807-9342

Volume 14, N. 2, 2018

outro lado, as questões urbana e ambiental não acompanharam essa ascensão econômica, havendo graves passivos ambientais (poluições) e urbanos (enchentes, segregação socioespacial e outros), que precisam ser questionados e solucionados.

\section{EDUCAÇÃO GEOGRÁFICA E O ESTUdO DA CIDADE E DO URBANO}

Dentro do ensino de geografia, há uma grande preocupação e importância no que tange ao diálogo acerca dos conteúdos e conceitos geográficos com o cotidiano dos alunos, possibilitando uma melhor leitura e entendimento de mundo.

Diariamente os estudantes percorrem vários espaços, adquirindo diferentes conhecimentos e informações em sua estrutura cognitiva. Nesse sentido, segundo Castellar (1999), ao trabalhar os conteúdos e os conceitos geográficos, os professores não devem negligenciar esse conhecimento prévio dos alunos, mas buscar organizar, programar e dar sequência de forma que possam realizar uma aprendizagem significativa, encaixando novos conhecimentos em sua estrutura cognitiva prévia, evitando, portanto, não reproduzir uma aprendizagem baseada na memorização.

A cidade passa a ser um espaço educativo importante para a construção do conhecimento geográfico, pois nela ocorrem as práticas espaciais dos alunos, que consomem e produzem suas identidades, observando a diferenciação estrutural nos bairros, criando laços afetivos, entre outras questões.

Assim, Callai (2011) argumenta que as diferentes espacialidades dos estudantes pela cidade permitem ao docente trabalhar com conceitos importantes na Geografia, como território, paisagem, lugar, questões urbana e ambiental, entre outras análises. Castellar; Vilhena (2010) argumentam ainda que, estudar a cidade permite problematizar vários fenômenos que ocorrem no espaço geográfico, nos âmbitos urbano, social e ambiental.

Ter a cidade como um objeto de estudo geográfico é estudar seus sistemas de entradas e saídas suas vias de acesso em vários pontos; as inter-relações com as aglomerações populacionais; a dinâmica econômica e cultural de seus moradores- que gera as características particulares dos bairros-; as relações socioambientais que se estabelecem; os serviços públicos e os problemas causados pela ausência deles. O quadro da saúde pública; em suma, os diversos elementos que compõem a paisagem do lugar (CASTELLAR; VILHENA, 2010, p. 123). 


\section{REVISTA ELETRÔNICA \\ DA GRADUAÇÃO/PÓS-GRADUAÇÃO EM EDUCAÇÃO UFG/REJ}

\section{ITINERARPIUIS REFLECTIONIS}

ISSN. 1807-9342

Volume 14, N. 2, 2018

Segundo Lefebvre (2008), a cidade já existia antes da industrialização. A construção da primeira se dá por meio das relações sociais, que constroem as múltiplas territorialidades ao longo do espaço geográfico. Souza (2005) argumenta que, definir a cidade é algo muito complexo, pois nela ocorrem os assentamentos humanos diversificados, ou seja, diferentes tipos de atividade, como o uso do solo, as atividades econômicas, o espaço de produção não-agrícola, de comércio, de oferecimento de serviços, e outros.

Nessa perspectiva, segundo Sacramento (2012, 2014), estudar a cidade em sua multiplicidade, no ensino de geografia, é promover articulação dos conceitos e conteúdos didáticos com os fenômenos que estão espacializados na própria dinâmica da cidade.

Por isso, ao estudar o contexto do município de Duque de Caxias, há a possibilidade de despertar a curiosidade dos alunos sobre o município, pois será tratado o espaço em que eles vivem cotidianamente. Nesse sentido, segundo Cavalcanti (2012), a análise sobre o município pode ser sistematizada por meio de alguns elementos, como:

(...) o plano urbano, a densidade de população, as habitações e os imóveis de uso comercial, o equipamento de serviços, as características demográficas e étnicas e as características socioprofissionais, ou com elementos do que tenho chamado de dinâmica interna da cidade: a produção, a circulação e a moradia (CAVALCANTI, 2012, p.65).

O primeiro ponto importante sobre Duque de Caxias é o aluno compreender de que forma ocorre a produção do seu espaço urbano, entendendo algumas contextualizações, como a formação e as transformações espaciais, as contradições econômicas, culturais, ambientais e urbanas, entre outros casos. Portanto, um dos grandes objetivos é o estudante entender que o espaço urbano é resultado de um processo construído pela sociedade e, consequentemente, por ele mesmo. Desta forma, os conteúdos geográficos relacionados ao seu cotidiano passarão a ter significado e importância social, abrindo a possibilidade para análises, questionamentos e opiniões (BENTO, 2011). 


\section{REVISTA ELETRÔNICA \\ DA GRADUAÇÃO/PÓS-GRADUAÇÃO EM EDUCAÇÃO \\ UFG/REJ}

\section{ITINERARUIS REFLECTIONIS}

ISSN. 1807-9342

Volume 14, N. 2, 2018

O segundo elemento é abordar a construção do arranjo interno de Duque de Caxias, permitindo, pois, aos alunos, compreenderem que a edificação do espaço urbano é algo muito complexo e dinâmico, que depende das relações sociais e dos processos produtivos. Assim, entenderão que, no espaço urbano capitalista vivenciado por eles, existem diferentes usos da terra, como as áreas residências, rurais, industrias e outras. Poderão ainda entender que este referido espaço é produzido pelo Estado, pelos proprietários dos meios de produção, pelos grupos excluídos, entre outros agentes (CORRÊA, 1989).

Outro contexto importante de observação é a questão da desigualdade social em Duque de Caxias, ou ainda, a segregação socioespacial. Muitos alunos não entendem os motivos, por exemplo, do bairro Jardim Vinte e Cinco de Agosto possuir equipamentos públicos e estruturas físicas melhores que o bairro Jardim Gramacho. Logo, trabalhar o conceito de segregação socioespacial é de suma importância para que eles entendam que o espaço urbano é constituído de contradições que favorecem a exploração e acumulação do capital (LEFEBVRE, 2008). Para a afirmação dessa análise, poderão verificar que, em diferentes locais, as moradias na cidade recebem muito ou nenhum investimento público, a depender da classe social dos moradores naquela localidade.

Uma grande problemática observada na esfera urbana de Duque de Caxias, importante de enfatizar, é a questão ambiental. Devido ao grande crescimento industrial em um curto espaço de tempo pelo qual passou o município, acompanhado pela ausência de um planejamento urbano, consequências ambientais passaram a ser vivenciadas e visualizadas pelos alunos, como os distintos tipos de poluição.

Analisar a cidade na contradição espacial entre produção e consumo leva a considerar a questão ambiental. Sabe-se que essa questão, que tanto tem preocupado a sociedade nas últimas décadas é resultante de um determinado modo de produção que se fundamenta na criação e no consumo constante de mercadorias, o que requer o uso acentuado da natureza e seus recursos (CAVALCANTI, 2012, p. 68).

Sob esse aspecto, como argumenta a autora, o modo de produção capitalista visa a produzir o espaço urbano a partir da usurpação de recursos naturais, sem qualquer preocupação com os danos ambientais. Isto posto, é importante que os alunos compreendam que as várias problemáticas ambientais vivenciadas por eles e presentes em vários pontos do território duque-caxiense, são consequência do modo de produção 


\section{REVISTA ELETRÔNICA \\ DA GRADUAÇÃO/PÓS-GRADUAÇÃOO EM EDUCAÇÃO}

UFG/REJ

\section{ITHERARIIIS \\ REFLECTIONIS}

ISS N. 1807-9342

Volume 14, N. 2, 2018

capitalista, que sempre utilizou os recursos naturais para a produção de mercadorias, sem considerar os efeitos ambientais para o município e a população.

Assim sendo, vários são os conteúdos geográficos que podem ser tratados a respeito do município de Duque de Caxias. Segundo Cavalcanti (2012), a estruturação da cidade se dá de tal modo, que ela educa seus habitantes e pode fazê-lo, por exemplo, para a vida solidária ou, ao contrário, para o isolamento e a segregação.

Por isso, estudar cidade permitirá que os professores trabalhem com dois conceitos importantes para a geografia: o de identidade e o de lugar. Desse modo, os alunos poderão observar que espaços da cidade possuem arranjos espaciais diferentes e são apropriados de forma distinta por eles ou mesmo por um determinado grupo.

Algum elemento presente em determinado espaço da cidade fará com que eles se identifiquem, criando um laço afetivo. Em outros locais, a sua identidade poderá ser afetada, fazendo-os se sentir não pertencente àquele espaço da cidade. Por exemplo, há nas grandes cidades espaços de hip hop, de samba, que são apropriados por um grupo, mantendo-se uma identidade. Por outro lado, esse mesmo espaço pode não ser frequentado por outras pessoas, por estas não se identificarem pelo ritmo musical destas culturas.

Nessa perspectiva identitária, é importante o professor argumentar com os alunos que o conceito de identidade não é algo estável como fora um dia. Segundo a análise de Bento (2011), no mundo contemporâneo globalizado, graças às relações sociais, influências culturais e consumistas baseadas na lógica capitalista que perpetua o global no local, as pessoas mudam constantemente seus costumes e hábitos, e consequentemente, a sua identidade.

A partir dessas análises, afirmar a cidade como objeto da educação geográfica vai além do entendimento da produção espacial, das abordagens sobre as problemáticas urbano-ambientais, entre outros assuntos. $\mathrm{Na}$ verdade, há o incentivo à luta pelo direito à cidade, a um lugar mais democrático, já que este é vivenciado cotidianamente, apropriado e produzido pelos alunos, criando um laço afetivo.

A cidade faz parte da concepção humana de criação e organização de seu espaço. Nela se constituem vários objetos e fenômenos a serem interpretados, de acordo com as diferentes formas e conteúdos. Sendo, uma parte do espaço geográfico, ela traz signos, símbolos e informações culturais, sociais, econômicas que fazem parte das 


\section{REVISTA ELETRÔNICA}

DA GRADUAÇÃO/PÓS-GRADUAÇÃ̃O EM EDUCAÇÃO UFG/REJ

\section{ITHEERARIIUS \\ REFLECTIONIS}

ISS N. 1807-9342

Volume 14, N. 2, 2018

paisagens e dos arranjos territoriais no espaço (SACRAMENTO, 2014, p.104.)

Conforme a concepção desta autora, o ensino de geografia deve se preocupar com a construção de conceitos geográficos a partir do cotidiano dos alunos, desenvolvendo nestes o pensamento crítico em relação aos seus espaços. Assim, estudar cidade na educação geográfica é um importante método dialético que possibilita articular os conteúdos da geografia urbana com a prática espacial dos alunos, de maneira que estes compreendam a sociedade em que vivem, a sua história e o espaço por eles produzido.

Desta forma, consoante as análises de Castellar (2012), Cavalcanti (2012), Sacramento $(2012$; 2014), dentre outros autores, ensinar geografia não é possibilitar a fixação de conteúdos pelos estudantes, mas possibilitar o raciocínio geográfico baseado na observação, análise e questionamento; compreendendo os fenômenos culturais, econômicos, sociais e ambientais a partir do uso das diferentes escalas. Novamente, então, a cidade é uma importante ferramenta para a educação geográfica, pois, além de ser o local cotidiano dos alunos, auxilia no desenvolvimento de comportamentos e atitudes em relação aos espaços, em especial aos urbanos. Ademais, favorece a aquisição de informações e a formação de conceitos importantes no desenvolvimento espacial e uma melhor leitura de mundo.

\section{O USO DAS IMAGENS: compreendendo as particularidades da cidade de duque de Caxias - $R J$}

Para desenvolver as atividades, buscamos realizá-las a partir da metodologia das oficinas pedagógicas, que têm como intuito serem espaços de reflexão e aprendizagem sobre a prática pedagógica, uma vez que promovem as diferentes maneiras do uso da investigação, produção e utilização de materiais pedagógicos, que auxiliam, por sua vez, no processo de ensino-aprendizagem. Logo, a atividade elaborada pelo docente se torna mais dinâmica e incentivadora, causando maior interação entre aquele e o discente.

Desta maneira, a metodologia de aplicação de oficinas é uma forma de tornar os estudantes sujeitos ativos na aprendizagem. Segundo Paviani; Fontana (2009), 


\section{REVISTA ELETRÔNICA \\ DA GRADUAÇÃO/PÓS-GRADUAÇÃO EM EDUCAÇÃO UFG/REJ}

\section{ITHEERARIIUS \\ REFLECTIONIS}

ISS N. 1807-9342

Volume 14, N. 2, 2018

oficina é, pois, uma oportunidade de vivenciar situações concretas e significativas, baseada no tripé: sentir-pensar-agir, com objetivos pedagógicos. Nesse sentido, a metodologia da oficina muda o foco tradicional da aprendizagem (cognição), passando a incorporar a ação e a reflexão. Em outras palavras, numa oficina ocorrem a apropriação, construção e produção de conhecimentos teóricos e práticos, de formativa e reflexiva. (PAVIANI; FONTANA, 2009, p. 2)

Conforme as autoras, as oficinas têm duas finalidades básicas: a articulação de conceitos, pressupostos e noções com ações concretas, vivenciadas pelo estudante; e a vivência e execução de tarefas em equipe, ou seja, uma construção coletiva do conhecimento.

Todos os segmentos escolares podem trabalhar com oficinas em vários assuntos, desde que haja o desenvolvimento de atividades práticas em sala de aula. Consequentemente, os estudantes se interessam mais quando existe a possibilidade de uso e expressão de suas opiniões sobre o que assimilaram durante o processo educativo, através do material disponibilizado em uma atividade.

A parte teórica foi o primeiro passo para a realização da respectiva pesquisa. Foram selecionadas bibliografias que retratavam a respeito das temáticas argumentadas ao longo do trabalho, como: a produção do espaço urbano; contextualização do município de Duque de Caxias; a educação geográfica; a importância de estudar cidade na educação geográfica e, por último, o auxílio dos recursos didáticos no processo de ensino-aprendizagem, no caso deste trabalho, do uso das imagens de Duque de Caxias.

O segundo momento foi a escolha do bairro Taquara, localizado no município de Duque de Caxias, região metropolitana do Rio de Janeiro. O público alvo da pesquisa foi composto por alunos de duas turmas do terceiro ano do ensino médio (3001 e 3002), do Colégio Estadual Nova América, localizado no mesmo bairro. O colégio pertence à rede estadual de ensino, funcionando em três turnos (manhã, tarde e noite), e possuindo aproximadamente 600 alunos. A execução das atividades contou com a participação de aproximadamente 30 estudantes, com idades entre 17 e 30 anos.

A primeira etapa para a realização da oficina "Os problemas urbanos e ambientais de Duque de Caxias" se deram através da análise das respostas dos estudantes, para que assim fosse possível escolher os conteúdos a serem trabalhados na oficina no dia 19.10.2015. 


\section{REVISTA ELETRÔNICA \\ DA GRADUAÇÃO/PÓS-GRADUAÇÃO EM EDUCAÇÃO UFG/REJ}

\section{ITINERARUIS REFLECTIONIS}

ISS N. 1807-9342

Volume 14, N. 2, 2018

Para a realização da oficina neste dia foram utilizadas as imagens do município, a fim de mediar o processo de ensino. Por conseguinte, pode-se observar a importância que as imagens tiveram para a sua realização e, posteriormente, para análise das respostas da atividade realizada pelos alunos.

Para a mediação do ensino sobre os problemas urbanos e ambientais de Duque de Caxias, as imagens tiveram impactos positivos, possibilitando a participação ativa dos estudantes, que mostraram um nível maior de opiniões e questionamentos. Nesse contexto, como argumentam Girão; Lima (2013), as imagens foram um importante material didático que proporcionou aos alunos a capacidade analítica e de opinião sobre os fenômenos representados no espaço geográfico.

Partindo-se da ideia dos autores supracitados, as imagens foram utilizadas concomitantemente aos assuntos tratados, permitindo melhor compreensão dos conteúdos e abrindo possibilidades para sugestões, opiniões e críticas. Por exemplo, enquanto se falava acerca dos agentes produtores do espaço urbano do município, o crescimento urbano de Duque de Caxias e suas consequências urbanas e ambientais, mostravam-se imagens juntamente a essas respectivas temáticas.

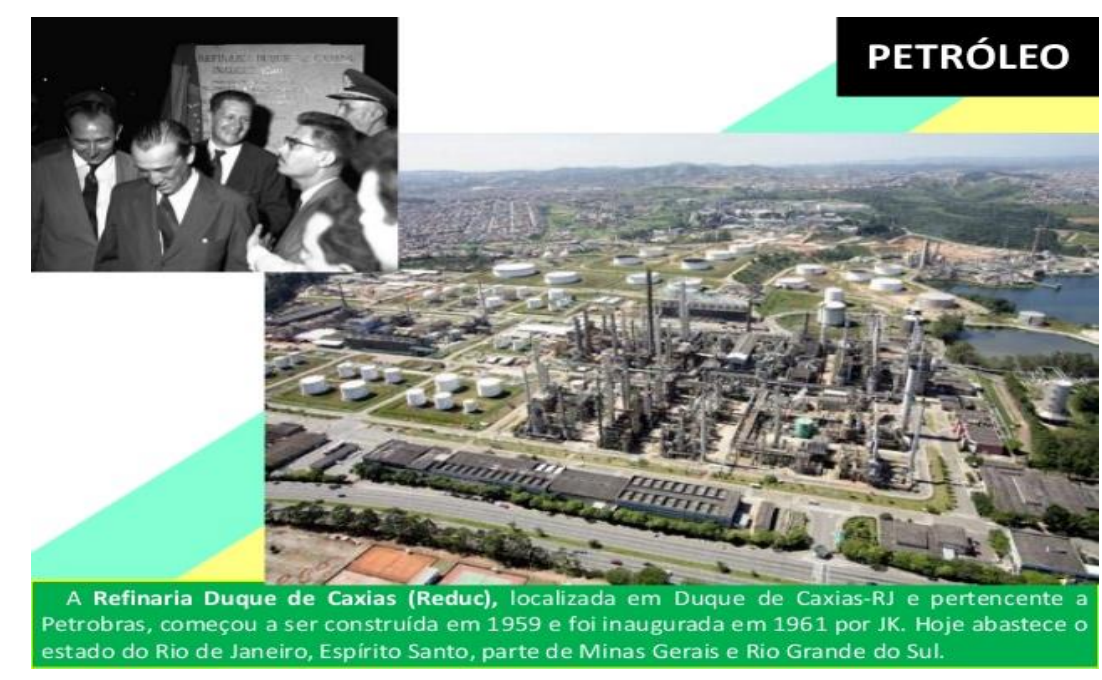

Imagem 1: Nesta imagem observa-se a presença da refinaria no município de Duque de Caxias (Reduc), inaugurada pelo presidente JK em 1961. Nesse sentido, afirma-se que os investimentos estatais foram um dos principais agentes produtores do espaço urbano de Duque de Caxias.

Fonte: http://pt.slideshare.net/cris tianopis solato/314-abcd-periodo-democratico-gov-kubitschek 


\section{REVISTA ELETRÔNICA \\ DA GRADUAÇÃO/PÓS-GRADUAÇÃOO EM EDUCAÇÃO UFG/REJ}

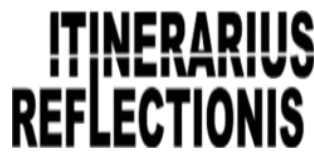

ISSN. 1807-9342

Volume 14, N. 2, 2018
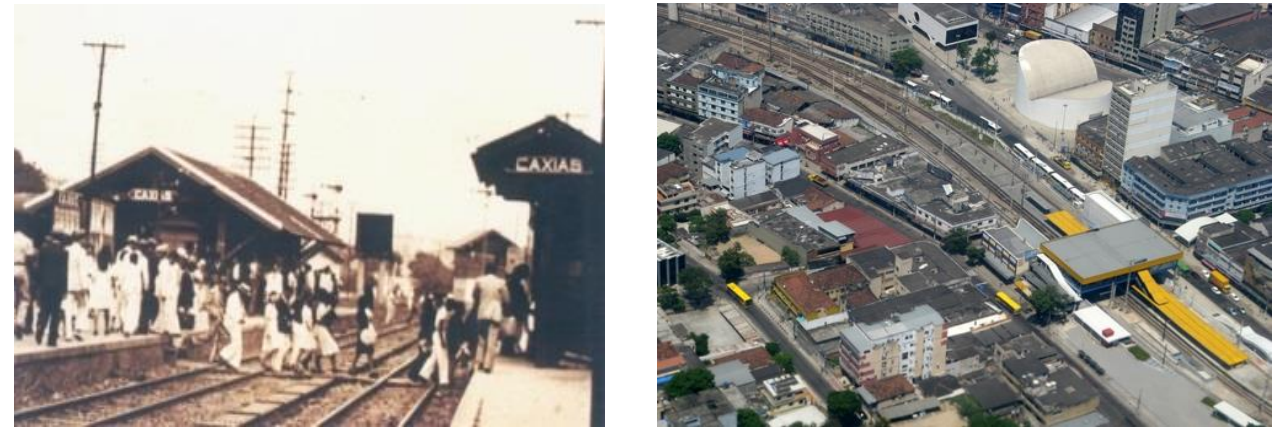

Imagem 2: Nessas imagens observam-se as transformações espaciais no centro de Duque de Caxias. Fonte: Google imagens
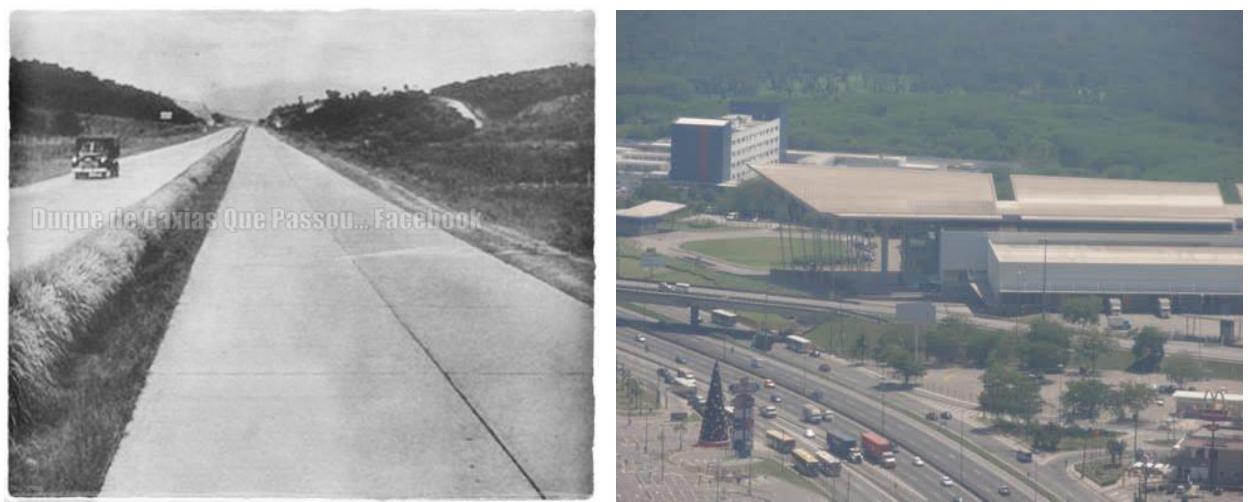

Imagem 3: Nessas imagens pode-se notar as transformações espaciais na altura da rodovia BR-040, que corta o município de Duque de Caxias. Atualmente, a mesma dá acesso ao centro do município, aos shoppings, hospitais e outros serviços. Fonte: Google imagens
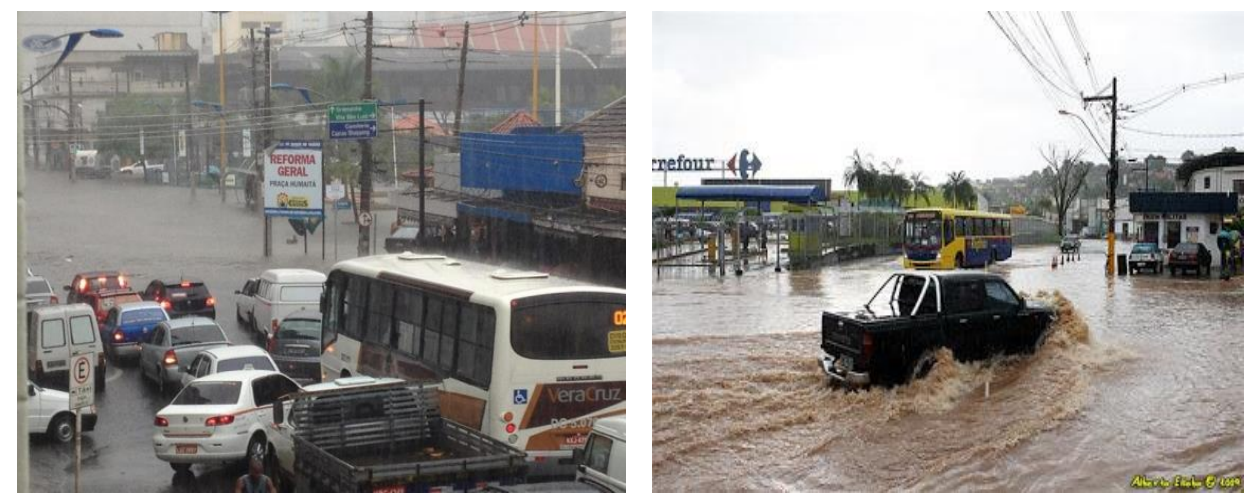

Imagem 4: Imagens representando os alagamentos nos bairros Jardim Vinte e Cinco de Agosto e Vila São Luís, respectivamente. Fonte: Google imagens

Assim, para cada assunto argumentado, uma imagem era usada concomitantemente. Portanto, elas não foram utilizadas meramente com caráter ilustrativo, tendo, na verdade, sentido didático e sendo coerente com o que foi ensinado, como bem destaca Castellar; Vilhena (2010): 


\section{REVISTA ELETRÔNICA \\ DA GRADUAÇÃO/PÓS-GRADUAÇÃO EM EDUCAÇÃO UFG/REJ}

\section{TTHERAPIIIS REFLECTIONIS}

ISS N. 1807-9342

Volume 14, N. 2, 2018

O uso das imagens deve ser o ponto de partida para a análise de um fenômeno que quer estudar em geografia, ou seja, que esteja associado ao conteúdo. Dessa maneira, o aluno será estimulado a fazer observações, a levantar hipóteses em face do tema abordado. Dessa forma, pode-se estabelecer critérios no momento da escolha das imagens (CASTELLAR; VILHENA, 2010, p. 81).

Ao término da apresentação da oficina com a utilização das imagens, os alunos tiveram que realizar uma atividade com o objetivo de analisar os benefícios que estas tiveram para o processo de ensino-aprendizagem, bem como para a assimilação dos conteúdos trabalhados.

No desenvolvimento da assertiva "Diante dos conteúdos trabalhados e a partir da observação das imagens apresentadas, discorram em uma folha separada sobre a seguinte frase: 'Duque de Caxias: desenvolvimento econômico não se reflete em desenvolvimento social e ambiental'", tem-se respostas como:

O município de Duque de Caxias tem uma economia considerada até boa, se comparada com alguns municípios. O único problema é que boa parte dessa renda acaba sendo desviada, isso acontece em muitos municípios, infelizmente. Devido ao crescimento da cidade, a poluição acaba sendo visível. Muitos rios estão poluídos por conta das pessoas que jogam lixo nesses rios, isso acontece pela coleta malfeita, e por certo, indústrias que se instalaram na cidade (Grupo 1, turma 3003).

$\mathrm{Na}$ primeira resposta dos alunos da turma 3003, nota-se que eles argumentaram primeiramente sobre a força econômica do município de Duque de Caxias, para em seguida, criticarem a ação dos governantes no que se refere ao desvio de dinheiro, uma vez que aqueles deixam de investir no benefício para a população. Posteriormente, destacaram o crescimento do município através de instalações de empresas, a má educação das pessoas ao jogar lixo nos rios, e a coleta de deste, que é mal feita pela prefeitura. Tais fatores geram consequências ambientais, como por exemplo, a poluição.

Desde as principais imagens do município de Caxias, já era negligente com a população e o meio ambiente, com o passar do tempo essa cidade foi muito vista por empresas multinacionais, que fugindo do alto imposto do capital e do amplo terreno e da 


\section{REVISTA ELETRÔNICA \\ DA GRADUAÇÃO/PÓS-GRADUAÇÃO EM EDUCAÇÃO UFG/REJ}

\section{ITINERPARIIUS REFLECTIONIS}

ISSN. 1807-9342

Volume 14, N. 2, 2018

proximidade da capital. Mas esse lugar tem muita desigualdade por ser o segundo município que mais fatura no Estado do Rio de Janeiro e muitos prefeitos entram e saem do poder e não fazem uma revitalização nesse lugar com tanto dinheiro, mas não melhoram! Entram em um círculo que nunca acaba e o povo continua carente e sem opção (Grupo 1, Turma 3002).

Os alunos Carlos, Felipe e Fernando da turma 3002 deram outros elementos para sua resposta. Segundo eles, desde os primórdios, Duque de Caxias era negligente com a população e o meio ambiente. Com o passar do tempo, o município foi atraindo empresas devido aos fatores locais favoráveis, como a proximidade com a capital do Rio de Janeiro e a oferta de terrenos. Por fim, destacaram que o espaço urbano do município é caracterizado por desigualdades, mesmo sendo um dos mais ricos do estado.

O município de Duque de Caxias é muito rico tanto no nosso estado quanto para o Brasil, mas toda essa riqueza não há investimento na cidade, tendo muitas ruas sem asfalto, esgoto a céu aberto. Fora as empresas que se instalaram no município que acabaram poluindo mais os nossos rios. O prefeito deveria investir melhor para a população com todo esse dinheiro (Grupo 2, turma 3002).

Segundo os alunos David e Luis da turma 3002, Duque de Caxias é um município rico economicamente, tanto na esfera estadual quanto federal. Por outro lado, criticam a administração dessa riqueza, argumentando que a mesma não é utilizada para o benefício da população, que ainda sofre com a ausência de saneamento básico. Destacam também a parcela de culpa das empresas no município, responsabilizando-as pelas degradações ambientais.

Caxias cresce muito nos últimos anos onde muitas pessoas e empresas vieram para cá. Hoje em dia é um município rico economicamente. Infelizmente a população sofre muito com a falta de hospital, escola e área de lazer. Nossos rios estão todos poluídos e quando chove os bairros sofrem com as enchentes (Grupo 2, Turma 3001).

$\mathrm{Na}$ última resposta, os alunos apontaram primeiramente o crescimento do município de Duque de Caxias, exemplificando com a chegada de pessoas e empresas no município. Em seguida, enfatizaram o paradoxo que o município vive, possuindo 


\section{REVISTA ELETRÔNICA}

DA GRADUAÇÃO/PÓS-GRADUAÇÃ̃O EM EDUCAÇÃO

UFG/REJ

\section{ITHEERAPIIIS \\ REFLECTIONIS}

ISS N. 1807-9342

Volume 14, N. 2, 2018

uma forte riqueza econômica, mas com acentuados problemas estruturais e ambientais, como a falta de hospitais, escolas, áreas de lazer, a poluição de rios e as constantes enchentes nos bairros.

Após analisar algumas das respostas, pode-se afirmar a coerência na sua elaboração para o que foi proposto, uma vez que os alunos entenderam e perceberam que economicamente o município de Duque de Caxias possui dados muito favoráveis, mas que essa riqueza não se reflete em desenvolvimento social e ambiental. Igualmente, argumentaram que o espaço urbano do município é caracterizado por muitas contradições nos aspectos urbano e ambiental, como a falta de saneamento básico e as diversas formas de poluição, em que as mesmas não estão relacionadas à falta de dinheiro, mas à ausência do compromis so dos governantes com a população.

\section{CONSIDERAÇÕES FINAIS}

Nesse sentido, pode-se argumentar que a utilização das imagens juntamente aos conteúdos trabalhados, favoreceu melhor assimilação e construção das respostas pelos discentes. Desta forma, no decorrer da apresentação da oficina, pode-se notar que as imagens prenderam a atenção dos alunos, motivando a participação destes através de perguntas, curiosidades, dúvidas e opiniões. Como consequência, os conteúdos se tornaram interessantes para eles, permitindo-lhes "gravar" melhor os assuntos trabalhados.

Logo, como afirmaram Dantas; Morais (2007), a imagem ultrapassa o código da escrita e se instaura no seio do processo educativo, trazendo à superfície o que já se sabia, mas pouco se explorava, ou seja, o fato de que "ver precede as palavras".

Partindo-se desse pressuposto, pode-se apontar que, ao abordar os conteúdos sobre Duque de Caxias juntamente à utilização das imagens, contribuiu-se igualmente para respostas mais coerentes e críticas. Em vez de os alunos terem só ouvido, ao visualizar os vários contextos geográficos que estavam sendo tratados a respeito do município, houve também o surgimento de questões e maior grau de curiosidade.

Portanto, a uso das imagens na oficina sobre os problemas urbanos e ambientais de Duque de Caxias possibilitou que os conteúdos geográficos referentes ao município fossem trabalhados de forma dialogada, permitindo aos alunos conhecerem um pouco acerca das problemáticas do seu cotidiano, despertando a capacidade de analisar e 


\section{REVISTA ELETRÔNICA \\ DA GRADUAÇÃO/PÓS-GRADUAÇÃO EM EDUCAÇÃO}

UFG/REJ

\section{ITHERARIIS REFLCTIONIS}

ISS N. 1807-9342

Volume 14, N. 2, 2018

criticar. Assim, como Girão; Lima (2013) afirmam, a imagem é uma ferramenta que aproxima o observador, possibilitando-o construir e reconstruir seus conceitos, ao passo que aprofunda a sua observação, análise e reanálise, sendo, talvez, a forma mais eficaz para se entender o mundo e suas mudanças.

\section{AGRADECIMENTOS}

Agradecimentos à CAPES e UERJ pela bolsa no Programa Institucional de Bolsa de Docência no subprojeto Geografia - UERJ-FFP) de 2014-2016.

\section{REFERÊNCIAS}

BENTO, Izabella Peracini. Estudar a cidade e seus sujeitos para aprender geografia. In: MORAIS, Eliana Marta Barbosa. CAVALCANTI, Lana de Souza. A cidade e seus sujeitos. Goiânia: Editora Vieira, 2011, p. 71-88.

BRAZ, Antonio Augusto; ALMEIDA, Tania Maria Amaro. De Merity a Duque de Caxias: Encontro com a história da cidade. Duque de Caxias-RJ. APPH-Clio,2010.

CALLAI, Helena Copetti. Em busca de fazer a educação geográfica. In: Helena Copetti Callai. (Org.). Educação geográfica-reflexão e prática. 1ed.Ijui: Editora Unijui, 2011, v. 1, p. 15-33.

CASTELLAR, Sônia. VILHENA, Jerusa. Um breve referencial teórico e a educação geográfica. In: Ensino de Geografia. $1^{\circ}$ ed. São Paulo, editora Cengage Learning, 2010, p.1-22.

CASTELLAR, Sonia Maria Vanzella. A Formação de Professores e o Ensino de Geografia. In: As transformações no mundo da educação: geografia, ensino e responsabilidade social. AGB: Associação dos Geógrafos Brasileiro, SP, 1999, p. 51 59.

CAVALCANTI, Lana de Souza. A geografia escolar e a cidade: Ensaios sobre o ensino de geografia para a vida interna cotidiana. $3^{\mathrm{a}}$ ed. Campinas, SP: Papirus, 2012.

CORRÊA, Roberto Lobato. O espaço urbano. Editora Ática S.A, São Paulo, 1989.

DANTAS, Eugênia Maria. MORAIS, Ione Rodrigues Diniz. O ensino de geografia e a imagem: universo de possibilidades. In: IX Colóquio Intemacional de Geocrítica. Porto Alegre 2007. s/p. 


\section{REVISTA ELETRÔNICA \\ DA GRADUAÇÃO/PÓS-GRADUAÇÃO EM EDUCAÇÃO UFG/REJ}

GIRÃO, Osvaldo. LIMA, Surama Ramos. O ensino de Geografia versus leitura de imagens: resgate e valorização da disciplina pela "alfabetização do olhar". UFSM: Geografia Ensino \& Pesquisa, vol. 17, .2, maio/ago, p.88-106, 2012.

HARVEY, David. A geografia da acumulação capitalista: uma reconstrução da teoria marxista. In: A produção capitalista do espaço. Ed. Annablume, São Paulo, 2005, p. 41-73.

LEFEBVRE, Henri. Industrialização e urbanização- Noções Preliminares. In: O direito à cidade. $5^{\mathrm{a}}$ edição. São Paulo: Editora Centauro, 2008, p. 11-34.

PAVIANI, Neires M. S. e FONTANA, Niura M. Oficinas pedagógicas: relato de uma experiência. Conjectura, Caxias do Sul, v. 14, n. 2, maio/ago, p. 77-88, 2009.

SACRAMENTO. Ana Claudia Ramos. Diferentes Linguagens na Educação Geográfica da Cidade do Rio de Janeiro. Revista Continentes (UFRRJ), ano 1, n.1, p. 97-118, 2012.

SACRAMENTO, Ana Claudia Ramos. A mediação didática do estudo da cidade e o trabalho de campo: diferentes formas de ensinar geografia. In: CASTELLAR, Sonia. (Org.). Geografia Escolar: contextualizando a sala de aula. 1ed.Curitba: CRV, 2014, v. 1 , p. 103-118.

SANTOS, Milton. A população urbana. In: Manual de geografia urbana. Editora USP. $3^{\circ}$ ed. 2008.

SOUZA, Marcelo Lopes. ABC do desenvolvimento urbano. $2^{\text {a }}$ edição. Rio de Janeiro: Bertrand, Rio de Janeiro, 2005. 